\title{
IL-35 may maintain homeostasis of the immune microenvironment in periodontitis
}

\author{
YING JIN, DIXIN LIU and XIAOPING LIN \\ Department of Stomatology, Shengjing Hospital of China Medical University, Shenyang, Liaoning 110004, P.R. China
}

Received December 16, 2016; Accepted June 29, 2017

DOI: $10.3892 /$ etm.2017.5255

\begin{abstract}
T lymphocyte cells, including regulatory T (Treg) and $\mathrm{T}$ helper 17 cells, have important roles in the human periodontium. However, the basis for Treg cytokine expression in various compartments of the periodontium remains unclear. The aim of the present study was to investigate the expression of interleukin (IL)-35 in the peripheral blood mononuclear cells (PBMCs) and periodontal tissues of patients with chronic periodontitis $(\mathrm{CP})$, with a view to understanding its role in this disease, and ultimately providing improved treatments. Peripheral blood, periodontal tissues and gingival crevicular fluids (GCFs) were collected from patients with CP or impacted teeth, the latter serving as healthy controls. The expression levels of IL-35 subunit mRNAs in PBMCs and periodontal tissues were determined using reverse transcription-quantitative polymerase chain reaction, while the IL-35 protein expression in GCFs and sera was quantified by ELISA. The relative expression of IL-35 subunit mRNAs in the affected tissues of patients with $\mathrm{CP}$ was significantly higher compared with that in samples from healthy controls $(\mathrm{P}<0.05)$. The mean concentration of IL-35 protein in the GCFs and sera of patients with periodontitis was also significantly higher compared with that in samples from healthy controls $(\mathrm{P}<0.001)$. IL-35 protein and periodontal clinical indicators were negatively correlated. It was hypothesized that the increased level of IL-35 plays a protective role in periodontal disease by maintaining immune system homeostasis and dampening the inflammatory response, and highlights IL-35 as a potential new therapy for the treatment of periodontitis.
\end{abstract}

\section{Introduction}

Chronic periodontitis (CP) is an infectious disease that affects the periodontium and gradually destroys periodontal tissues (1). Bacterial plaque is a well-known cause of CP,

Correspondence to: Dr Xiaoping Lin, Department of Stomatology, Shengjing Hospital of China Medical University, 36 San Hao Street, Shenyang, Liaoning 110004, P.R. China

E-mail: xiaoping_ba@126.com

Key words: interleukin-35, Foxp3, chronic periodontitis, Treg cells which stimulates a local inflammatory response and activation of the innate immune system $(1,2)$. This eventually results in the characteristic pathology of periodontal disease, the main clinical features of which are advancing gingival inflammation, irreversible alveolar bone loss, and the loosening and/or loss of teeth (3). Numerous studies $(4,5)$ have highlighted the role of $\mathrm{T}$ lymphocyte cells in periodontitis; in particular, $\mathrm{T}$ lymphocyte phenotype and function are important in the susceptibility, onset and severity of periodontitis (6).

Regulatory T (Treg) cells are a critical sub-population of $\mathrm{CD}^{+} \mathrm{T}$ cells that are essential for maintaining self-tolerance and preventing autoimmunity, for limiting chronic inflammatory diseases, and for regulating homeostatic lymphocyte expansion (7-11). A recent study by Wang et al (12) demonstrated that the imbalance between Treg cells and $\mathrm{T}$ helper 17 (Th17) cells plays an essential role in the progression of periodontitis.

Interleukin (IL)-35, as a Forkhead box P3 (Foxp3) ${ }^{+}$Treg cell immunosuppressive/anti-inflammatory cytokine, is required for the maximum regulatory activity of Treg cells (13). IL-35 is a heterodimer formed by an IL-12p35 subunit and an IL-27 $\beta$ chain, the latter of which is encoded by the Epstein-Barr virus-induced 3 (EBi3) gene (14). The known functions of IL-35 include: Maintenance of the peripheral immune system; regulation of the proliferation of $\mathrm{T}$ effector cells; inhibition of Th17 cell differentiation and IL-17 synthesis (15). Thus, it has a close association with immunological and infectious diseases $(16,17)$. Although studies on IL-35 are relatively few, and the signal transduction mechanisms involved in its actions are not yet elucidated, IL-35 therapy shows promising potential for the treatment of immunological and infectious diseases $(15,18)$.

In the present study, the expression of Foxp3, IL-12p35 and EBi3 mRNA in peripheral blood mononuclear cells (PBMCs) and periodontal tissue, and the concentration of IL-35 protein in serum and gingival crevicular fluid (GCF), were compared between patients with $\mathrm{CP}$ and healthy individuals. Elucidating the potential signaling mechanisms of IL-35 in CP may provide a basis for improvements in the future clinical treatments of periodontitis.

\section{Materials and methods}

Study population. The study included 20 patients with CP (the $\mathrm{CP}$ group) and 20 healthy individuals (the control group) at 
Shengjing Hospital of China Medical University (Shenyang, China). Participants were recruited from February to December 2013, and their ages ranged from 18 to 55 years. Subjects were included according to the following three criteria: i) A diagnosis of moderate to severe chronic periodontitis [moderate: $4 \mathrm{~mm}<$ pocket depth (PD) $\leq 6 \mathrm{~mm}$ and clinical attachment loss (CAL) 3-5 mm, or radiographic bone loss between one-third and one-half root length; severe: PD $>6 \mathrm{~mm}$ and CAL $>5 \mathrm{~mm}$, or radiographic bone loss $\geq$ one-half root length (19)]; ii) retention of $\geq 20$ teeth; iii) being generally healthy and without systemic disease. Exclusion criteria included: i) Recent intake of any pharmaceutical that had the potential to influence the outcome of the study or inflammatory clinical indices, e.g. antibiotics; ii) use of systemic antibiotics or local antimicrobial agents in the previous 3 months prior to the start of the trial; iii) pregnancy or lactation in female subjects; iv) received periodontal supportive treatment within 6 months prior to the start of the trial. The study protocol was approved by the Ethics Committee of Shengjing Hospital of China Medical University. All trial participants provided informed consent.

Clinical examination. To diagnose and document periodontal disease, trial participants were assessed for probing depth (PD) and clinical attachment level (CAL) by a single examiner using a Florida Probe system (Florida Probe Corporation, Gainesville, FL, USA). Testing was conducted for six sites per tooth for all teeth.

GCF and periodontal tissue collection. A tooth site without untreated caries, overhang fillings, food impaction or any inflammation with the exception of $\mathrm{CP}$ in each quadrant was selected. In the majority of cases the mesiobuccal site of the first molar was selected. If the first molar was not available, a second molar or a premolar in the same quadrant was selected. Plaque and chunks of calculus were removed and the tooth was then dried with dry, sterile cotton and an air gun. After waiting for $1 \mathrm{~min}$, a Whatman paper strip was inserted, until mild resistance was encountered, for GCF collection from a periodontal pocket. Each paper strip was left in its position for $30 \mathrm{sec}$. Paper strips contaminated with blood were discarded. Four paper strips were collected from each participant (a total of 80 sites from the CP or control groups) and inserted into an Eppendorf tube, $200 \mu 1 \mathrm{PBS}$ added and the tubes were then stored at $-80^{\circ} \mathrm{C}$.

Patients received local anesthesia and periodontal tissue biopsies were obtained by surgical excision from the labial/buccal surface of the gingival margin/papilla of multirooted teeth. Tissue biopsies from patients with periodontitis were collected with flap surgery. Healthy biopsies were also collected from patients following surgery for impacted teeth. Each tissue was repeatedly washed with $0.9 \%$ saline until blood was no longer seen, then $1 \mathrm{ml}$ of RNAiso Reagent (Takara Biotechnology Co., Ltd., Dalian, China) was added to each sample and the sample was stored in an RNase-free Eppendorf tube at $-80^{\circ} \mathrm{C}$.

Blood collection. Peripheral venous blood was drawn from each individual and collected in heparin tubes. PBMCs were isolated from $2 \mathrm{ml}$ blood by density gradient centrifugation using the separation medium Ficoll according to the manufacturer's instructions (Haoyang Biotechnology Co., Ltd.,
Table I. Primer sequences.

\begin{tabular}{lll}
\hline Target & Direction & \multicolumn{1}{c}{ Sequence (5'-3') } \\
\hline Foxp3 & Forward & CTGGCAAATGGTGTCTGCAAGT \\
& Reverse & CTGCCCTTCTCATCCAGAAGATG \\
IL-12p35 & Forward & AGGAATGTTCCCATGCCTTCA \\
& Reverse & CCAATGGTAAACAGGCCTCCAC \\
EBi3 & Forward & GACCTCACAGACTACGGGGAAC \\
& Reverse & CGGGAAGCCCTTGCTACTT \\
GAPDH & Forward & TGGTGAAGACGCCAGTGGA \\
& Reverse & GCACCGTCAAGGCTGAGAAC
\end{tabular}

Foxp3, Forkhead box P3; IL-12p35, interleukin 12 subunit p35; EBi3, Epstein-Barr virus-induced 3; GAPDH, glyceraldehyde-3-phosphate dehydrogenase.

Tianjin, China). Peripheral blood taken at rest was centrifuged $\left(20^{\circ} \mathrm{C}, 400 \mathrm{x} \mathrm{g}\right.$ for $\left.20 \mathrm{~min}\right)$ and serum aspirated into new tubes. PBMCs and sera were separately stored at $-80^{\circ} \mathrm{C}$ until use.

Reverse transcription-quantitative polymerase chain reaction $(R T-q P C R)$. PBMCs or 1- $\mathrm{mm}^{3}$ periodontal tissue samples were processed for total RNA extraction in $1 \mathrm{ml}$ RNAiso Reagent at $4^{\circ} \mathrm{C}$. RNA quality was determined using a bioanalyzer and total RNA was quantified using a spectrophotometer (Applied Biosystems; Thermo Fisher Scientific, Inc., Waltham, MA, USA) at $\mathrm{A}_{260 \mathrm{~nm}} / \mathrm{A}_{280 \mathrm{~nm}}$ between 1.8 and 2.0. RT was performed using a PrimeScript RT system (Takara Biotechnology Co., Ltd.) following the manufacturer's recommendations. The expression levels of I Foxp3, IL-12p35, EBi3 and glyceraldehyde-3-phosphate dehydrogenase (GAPDH) transcripts were quantified using RT-qPCR with SYBR Premix Ex Taq II (TaKaRa Biotechnology Co. Ltd.) and a LightCycler system (Roche Molecular Biochemicals, Mannheim, Germany) in accordance with the manufacturer's protocol. Primers for Foxp3, IL-12p35, EBi3 and GAPDH are listed in Table I. Cycling conditions used were: $95^{\circ} \mathrm{C}$ for $30 \mathrm{sec}, 95^{\circ} \mathrm{C}$ for $5 \mathrm{sec}$ and $60^{\circ} \mathrm{C}$ for $34 \mathrm{sec}$ for 40 cycles, then $95^{\circ} \mathrm{C}$ for $15 \mathrm{sec}, 60^{\circ} \mathrm{C}$ for $1 \mathrm{~min}$ and $95^{\circ} \mathrm{C}$ for $15 \mathrm{sec}$. In the qPCR process, $2 \mu \mathrm{l}$ cDNA was added per well, using three wells per sample. Relative target gene quantification was obtained according to the $2^{-\Delta \Delta C q}$ method (12). Target gene mRNA expression was normalized to GAPDH mRNA expression, and the adjusted expression for healthy individuals was used as a reference (fold change, 1). In the mRNA analysis, 20 patients per group were included.

Enzyme-linked immunosorbent assay (ELISA). Sera and GCFs were tested using an IL-35 ELISA kit (USCN, Co., Ltd., Wuhan, China) in strict accordance with the manufacturer's instructions. The optical density of each sample was determined at $450 \mathrm{~nm}$. A standard curve was generated, and data were expressed in units of $\mathrm{pg} / \mathrm{ml}$ IL-35 per liter of serum or GCF.

Statistical analysis. Data are expressed as the mean \pm standard error of the mean for each group. An unpaired Student's t-test was used to analyze differences between groups using SPSS 
Table II. Patient information and clinical parameters.

\begin{tabular}{lcccc}
\hline Group & Sample size & Age (years) & Sex (M/F) & PD (mm) \\
\hline Control & 20 & $35.23 \pm 2.36$ & $6 / 14$ & $1.60 \pm 0.05$ \\
CP & 20 & $37.12 \pm 2.55$ & $7 / 13$ & $4.72 \pm 0.26^{\mathrm{a}}$ \\
\hline
\end{tabular}

${ }^{\mathrm{a}} \mathrm{P}<0.05$ vs. control group. $\mathrm{CP}$, chronic periodontitis; $\mathrm{PD}$, probing depth; $\mathrm{CAL}$, clinical attachment level.

A

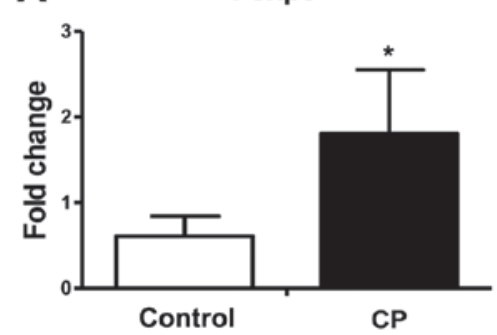

B

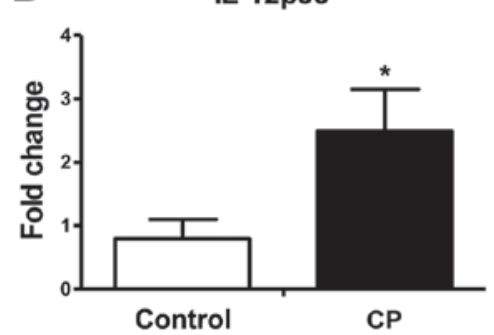

C

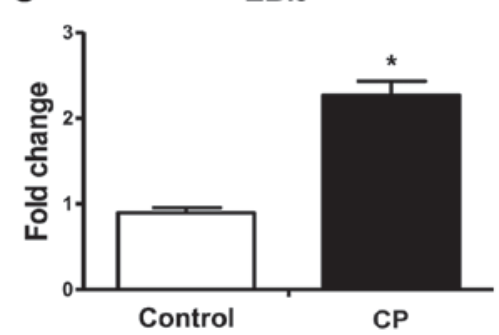

Figure 1. Foxp3, IL-12p35 and EBi3 mRNAs in periodontal tissues. (A) Foxp3, (B) IL-12p35 and (C) EBi3 mRNA expression in tissues of patients from the healthy control and CP groups. Healthy and periodontal tissue biopsies were collected from patients, mRNA extracted and reverse transcription-quantitative polymerase chain reaction performed using primers for Foxp3, IL-12p35 and EBi3 mRNAs. Data are expressed as the mean + standard error of the mean for each group $(\mathrm{n}=20)$. ${ }^{*} \mathrm{P}<0.05$ vs. control. Foxp3, Forkhead box P3; IL-12p35, interleukin 12 p35 subunit; EBi3, Epstein-Barr virus-induced 3; CP, chronic periodontitis.

A

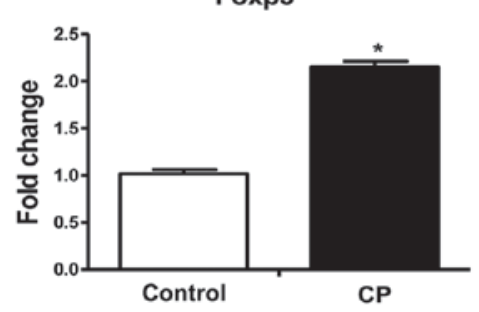

B

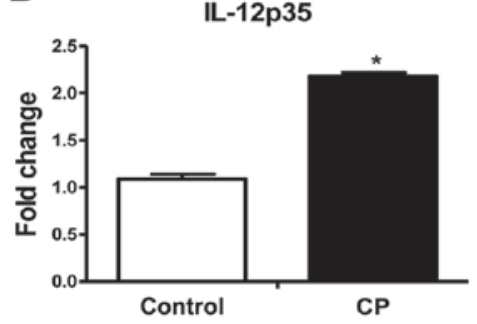

C

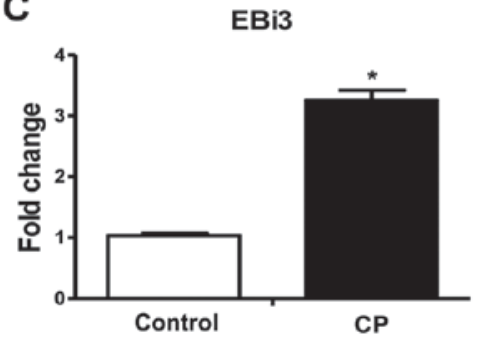

Figure 2. Foxp3, IL-12p35 and EBi3 mRNAs in PBMCs from patients. (A) Foxp3, (B) IL-12p35 and (C) EBi3 mRNA expression in PBMCs of patients from the healthy control and $\mathrm{CP}$ groups. Following the extraction of mRNA, reverse transcription-quantitative polymerase chain reaction was performed using primers for Foxp3, IL-12p35 and EBi3 mRNAs. Data are expressed as the mean + standard error of the mean for each group ( $\mathrm{n}=20$ ). ${ }^{\text {P }<0.05}$ vs. control. Foxp3, Forkhead box P3; IL-12p35, interleukin 12 p35 subunit; EBi3, Epstein-Barr virus-induced 3; CP, chronic periodontitis.

version 19.0 software (IBM Corp., Armonk, NY, USA). The correlation analysis between clinical indicators and cytokines was analyzed by the Pearson rank correlation test. $\mathrm{P}<0.05$ was considered to indicate a statistically significant result.

\section{Results}

Patient information and clinical parameters. A total of 40 participants were included in this study, with an age range from 18 to 55 years. Table II outlines the basic characteristics and clinical parameters of each group. The mean age of the CP group was $37.12 \pm 2.55$ years and that of the healthy group was $35.23 \pm 2.36$ years. The CP group consisted of 7 men and 13 women while the healthy group was composed of 6 men and 14 women. Differences in age and sex were not statistically significant between the two groups ( $\mathrm{P}>0.05$ for both). The PD of the healthy controls was $1.60 \pm 0.05 \mathrm{~mm}$ while for the $\mathrm{CP}$ group the PD was $4.72 \pm 0.26 \mathrm{~mm}$, a statistically significant increase $(\mathrm{P}<0.05)$. The mean $\mathrm{PD}$ and $\mathrm{CAL}$ for the $\mathrm{CP}$ group were significantly higher than those of the healthy group $(\mathrm{P}<0.05$ for both).

Foxp3, IL-12p35 and EBi3 mRNAs in periodontal tissues. The mRNA expression levels of Foxp3, and of the IL-35 subunits, IL-12p35 and EBi3, in periodontal tissue were analyzed using RT-qPCR. As shown in Fig. 1, significantly increased Foxp3, IL-12p35 and EBi3 mRNA expression in periodontal tissue (Foxp3, 2.21-fold; IL-12p35, 2.49-fold; EBi3, 2.27-fold; $\mathrm{P}<0.05$ for all) was observed for the CP group in comparison with the healthy control group.

Foxp3, IL-12p35 and EBi3 mRNA in PBMCs. The mRNA expression levels of Foxp3, IL-12p35 and EBi3 were also examined in PBMCs using RT-qPCR. As shown in Fig. 2, significantly increased Foxp3, IL-12p35 and EBi3 mRNA expression in PBMCs (Foxp3, 2.15-fold; IL-12p35, 2.17-fold; EBi3, 3.06-fold; $\mathrm{P}<0.05$ for all) was observed for the $\mathrm{CP}$ group in comparison with the healthy control group. 
IL-35 protein in GCF and serum. Table III and Fig. 3 show the mean levels of IL-35 protein in GCF and serum samples from the $\mathrm{CP}$ and healthy control groups. The mean concentration of IL-35 protein was $205.56 \pm 1.61 \mathrm{ng} / \mathrm{ml}$ in GCF and $330.42 \pm 4.30 \mathrm{ng} / \mathrm{ml}$ in serum from the CP group, while for the healthy control group it was $101.88 \pm 0.37 \mathrm{ng} / \mathrm{m}$ in GCF and $206.89 \pm 10.06 \mathrm{ng} / \mathrm{ml}$ in serum. The mean concentration of IL-35 protein in the GCF and serum was significantly higher for the CP group compared with the healthy group $(\mathrm{P}<0.001$ for both).

Correlation analysis. Using the Pearson rank correlation test, the concentration of IL-35 in the GCF with the CAL at detection sites of the $\mathrm{CP}$ group exhibited a negative correlation $\left(\mathrm{P}<0.001, \mathrm{R}^{2}=0.6101\right.$; Fig. $\left.4 \mathrm{~A}\right)$, and the concentrations of IL-35 and PD at detection sites were also significantly negative correlation $\left(\mathrm{P}<0.001, \mathrm{R}^{2}=0.6173\right.$; Fig. $\left.4 \mathrm{~B}\right)$. Similarly, the concentration of IL-35 in the serum of the CP group with CAL at detection sites exhibited a negative correlation $(\mathrm{P}<0.001$, $\mathrm{R}^{2}=0.9119$; Fig. 4C), and $\mathrm{PD}$ at detection sites was also negatively correlated with the concentration of serum IL-35 $\left(\mathrm{P}<0.001, \mathrm{R}^{2}=0.6812\right.$; Fig. 4D).

\section{Discussion}

Treg cells are necessary in the maintenance of immune homeostasis and the prevention of autoimmune disease. There is evidence $(20,21)$ to suggest that anti-inflammatory Treg cells also play an important role in the development of periodontal disease and are involved in the subsequent inflammation and bone resorption. The infiltration of Treg cells into periodontal tissue reflects their ability to inhibit tissue damage (22). Foxp3 plays an integral role in regulating the differentiation of Treg cells (23). In the present study, Foxp3 was detected in periodontal tissues and PBMCs using RT-qPCR and its expression was found to be significantly higher in the CP group compared with the healthy control group.

IL-35 is an immunosuppressive/anti-inflammatory cytokine, expressed by Foxp $3^{+}$Treg cells, that belongs to the IL-12 family of cytokines (24). IL-35 is a dimeric protein comprised of an $\alpha$ chain (p35) and a $\beta$ chain (EBi3) (14). Unlike other cytokines of the IL-12 family, IL-35 acts as an inhibitory factor for chronic inflammation, autoimmune disease and other immune disorders (7), and the expression of IL-35 in Treg cells is associated with their immune inhibitory ability (25). It has also been suggested that IL-35, as an inhibitory cytokine, plays a central role in infection and immune regulation (26), which includes inhibiting the proliferation of $\mathrm{T}$ cells and their effects. In the present study, it was observed that IL-35 was strongly detected in periodontitis tissues and the expression of IL-35 protein was increased in tissues from the $\mathrm{CP}$ group compared with those of healthy controls.

As long-living, non-Foxp3-dependent cells within the body, IL-35-producing inducible Treg cells secrete IL-35, which may inhibit the spread of inflammation, increase the number of Treg cell subsets and enhance immune regulation (27). Niedbala et al (15) found that an EBi3-p35-Fc fusion protein promoted the proliferation of $\mathrm{CD} 4^{+} \mathrm{CD} 25^{+}$Treg cells and inhibited $\mathrm{CD} 4^{+} \mathrm{CD} 25^{-} \mathrm{T}$ cells in vitro. These observations may explain why as increased expression of IL-35 protein in
Table III. Concentration of IL-35 protein in GCF and serum.

\begin{tabular}{lccc}
\hline Group & Sample size & GCF $(\mathrm{ng} / \mathrm{ml})$ & Serum $(\mathrm{ng} / \mathrm{ml})$ \\
\hline Control & 20 & $101.88 \pm 0.37$ & $206.89 \pm 10.06$ \\
CP & 20 & $205.56 \pm 1.61^{\mathrm{a}}$ & $330.42 \pm 4.30^{\mathrm{a}}$ \\
\hline
\end{tabular}

${ }^{\mathrm{a}} \mathrm{P}<0.05$ vs. control group. IL-35, interleukin 35; GCF, gingival crevicular fluid; $\mathrm{CP}$, chronic periodontitis.
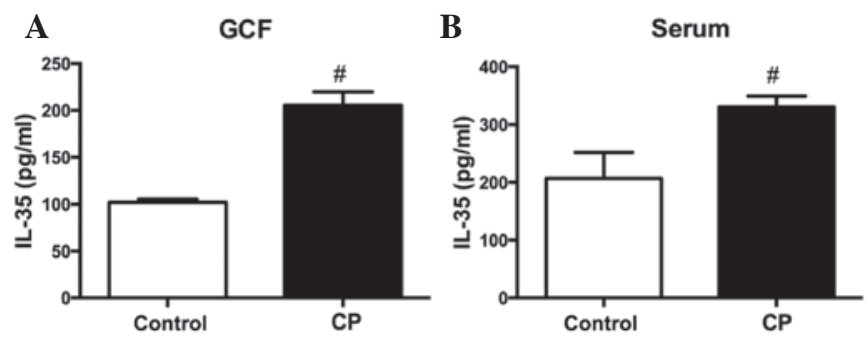

Figure 3. IL-35 protein in GCF and serum. The mean concentration of IL-35 protein in (A) GCF and (B) serum of patients from the healthy control and CP groups as determined using ELISA. Data are expressed as the mean + standard error of the mean for each group $(n=20)$. ${ }^{~} \mathrm{P}<0.001$ vs. control. IL-35, interleukin 35; GCF, gingival crevicular fluid; $\mathrm{CP}$, chronic periodontitis.
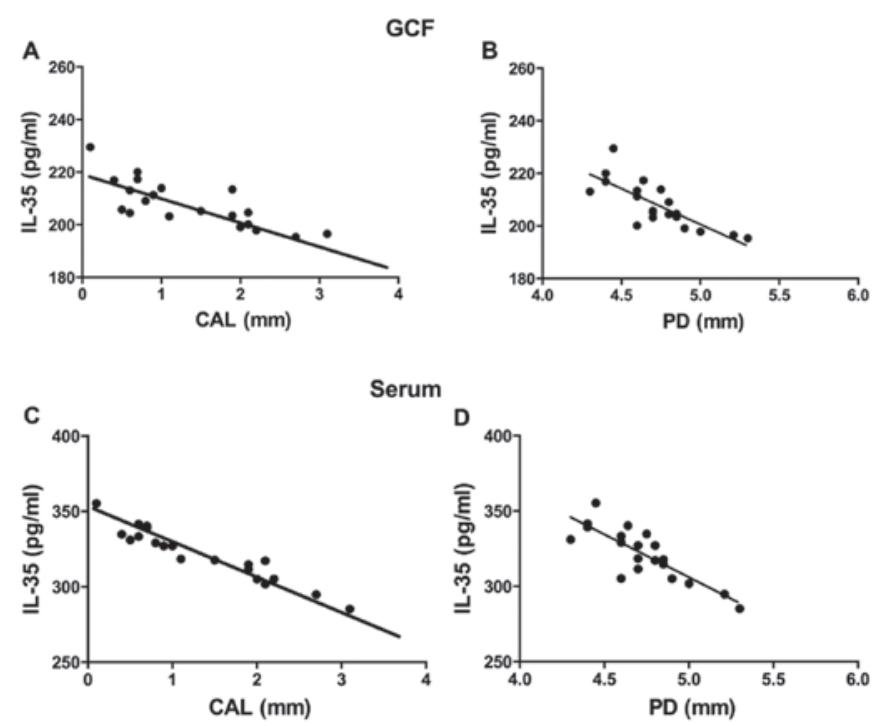

Figure 4. Correlation analysis of IL-35 protein and clinical examination results of patients with CP. Correlation of IL-35 with (A) CAL and (B) PD in the GCF, and with (C) CAL and (D) PD in serum. IL-35, interleukin 35; GCF, gingival crevicular fluid; $\mathrm{CP}$, chronic periodontitis; $\mathrm{CAL}$, clinical attachment level; PD, probing depth.

tissues from the CP group compared with those of healthy controls was detected in the present study.

There is evidence indicating that a loss of IL-35 is associated with the progression of various diseases, including numerous inflammatory diseases $(28,29)$. IL-35 is required for effective Treg cells; animals lacking functional IL-35 exhibit an enhanced inflammatory immune response and progressive deterioration from disease $(30,31)$. The present study found that the concentration of IL-35 in the GCF of the CP group 
showed a negative correlation with CAL or PD in detection sites, and the concentration of IL-35 in the serum of the CP group correlated with CAL and PD in a similar manner. These data suggest that IL-35 in autoimmune or infectious diseases may regulate the local microenvironment and peripheral immune response, maintaining its homeostasis.

The analysis of IL-12p35 and EBi3 (IL-35) mRNAs using RT-qPCR in PBMCs and periodontal tissues from patients with $\mathrm{CP}$ in the present study revealed significantly higher expression in the $\mathrm{CP}$ group compared with the healthy control group. This is a similar result to that of Kalburgi et al, which to the best of our knowledge is the only other study to address the role of IL-35 in periodontal disease, albeit using semi-quantitative RT-PCR (32). The present study also found that the mean concentration of IL-35 protein in GCFs and sera from the $\mathrm{CP}$ group was significantly higher than for the healthy group, paralleling gene expression. These results suggest that IL-35 is an essential factor for the immune response of Treg cells, and may be useful in the prognosis of CP. Similarly, Nakajima et al (33) reported that the proportion of $\mathrm{CD} 4{ }^{+} \mathrm{CD} 25^{+} \mathrm{T}$ cells and Foxp3 expression in periodontal disease tissues was increased compared with those of gingivitis controls. Since EBi3 is a downstream target of Foxp3 (7), the high expression of Foxp3 mRNA, as detected in the present study, would promote EBi3 subunit formation and therefore explain the high IL-35 protein expression that was observed.

The results of the present study indicate that IL-35 expression increases with CP development, which may help to attenuate the process of chronic periodontitis. In addition, although patients included in the study did not exhibit systemic disease, periodontitis may cause, or aggravate, chronic inflammation in systemic disease. More specifically, gram-negative anaerobic bacteria at the bottom of periodontal pockets may invade epithelial cells and hide in host cells, aggravating the destruction of periodontal tissue; they can potentially also invade endothelial cells and access the blood circulation to stimulate a host immune response and cause systemic inflammation (34-36). IL-35, as a negative regulator of immune factors, may slow or inhibit the development of periodontal disease and thus, indirectly, also slow systemic disease. IL-35 is a relatively recently identified cytokine that has not been studied in many disease models. Since the parameters investigated in the present study are few, it is unclear whether IL-35 enhances or antagonizes the effects of other cytokines or immune cells in CP. In future, it will be necessary to increase sample sizes and study a greater number of parameters to more fully understand the role of IL-35 in CP.

IL-35, as a Treg-specific suppressor of inflammatory cytokines, may maintain the balance between bacterial infection in chronic periodontal patients and effector cells by regulating the immune system, in order to avoid periodontal tissue damage caused by an overstimulated immune system $(24,32)$. The detection of higher levels of IL-35 protein and subunit mRNA in diseased tissue compared with healthy tissue indicate that it may play an important role in the development of CP. As GCF is easily sampled, and simple, sensitive and reliable detection methods for IL-35 are available, IL-35 is potentially an important diagnostic tool for clinical use. However, as an appropriate treatment strategy for periodontitis, further studies on IL-35 are required to understand the precise functional role of this cytokine in periodontal disease and within immune and inflammatory regulatory networks.

\section{Acknowledgements}

This study was supported by the Natural Science Foundation of China (grant no. 81570988).

\section{References}

1. Di Benedetto A, Gigante I, Colucci S and Grano M: Periodontal disease: Linking the primary inflammation to bone loss. Clin Dev Immunol 2013: 503754, 2013.

2. Mendes L, Azevedo NF, Felino A and Pinto MG: Relationship between invasion of the periodontium by periodontal pathogens and periodontal disease: A systematic review. Virulence 6: 208-215, 2015

3. Yucel-Lindberg $\mathrm{T}$ and Båge T: Inflammatory mediators in the pathogenesis of periodontitis. Expert Rev Mol Med 15: e7, 2013.

4. Gonzales JR: T- and B-cell subsets in periodontitis. Periodontol 2000 69: 181-200, 2015.

5. Campbell L, Millhouse E, Malcolm J and Culshaw S: T cells, teeth and tissue destruction - what do T cells do in periodontal disease? Mol Oral Microbiol 31: 445-456, 2016.

6. Hernández M, Dutzan N, García-Sesnich J, Abusleme L, Dezerega A, Silva N, González FE, Vernal R, Sorsa T and Gamonal J: Host-pathogen interactions in progressive chronic periodontitis. J Dent Res 90: 1164-1170, 2011.

7. Collison LW, Workman CJ, Kuo TT, Boyd K, Wang Y, Vignali KM, Cross R, Sehy D, Blumberg RS and Vignali DA: The inhibitory cytokine IL-35 contributes to regulatory T-cell function. Nature 450: 566-569, 2007.

8. Shevach EM, DiPaolo RA, Andersson J, Zhao DM, Stephens GL and Thornton AM: The lifestyle of naturally occurring CD4 ${ }^{+}$ $\mathrm{CD}_{25}{ }^{+} \mathrm{Foxp}^{+}{ }^{+}$regulatory T cells. Immunol Rev 212: 60-73, 2006

9. Xystrakis E, Boswell SE and Hawrylowicz CM: T regulatory cells and the control of allergic disease. Expert Opin Biol Ther 6: 121-133, 2006.

10. Coombes JL, Robinson NJ, Maloy KJ, Uhlig HH and Powrie F: Regulatory T cells and intestinal homeostasis. Immunol Rev 204: 184-194, 2005.

11. Annacker O, Pimenta-Araujo R, Burlen-Defranoux $\mathrm{O}$ and Bandeira A: On the ontogeny and physiology of regulatory $\mathrm{T}$ cells. Immunol Rev 182: 5-17, 2001

12. Wang L, Wang J, Jin Y, Gao H and Lin X: Oral administration of all-trans retinoic acid suppresses experimental periodontitis by modulating the Th17/Treg imbalance. J Periodontol 85: 740-750, 2014.

13. Collison LW and Vignali DA: Interleukin-35: Odd one out or part of the family? Immunol Rev 226: 248-262, 2008.

14. Choi J, Leung PS, Bowlus C and Gershwin ME: IL-35 and Autoimmunity: A comprehensive perspective. Clin Rev Allergy Immunol 49: 327-332, 2015

15. Niedbala W, Wei XQ, Cai B, Hueber AJ, Leung BP, McInnes IB and Liew FY: IL-35 is a novel cytokine with therapeutic effects against collagen-induced arthritis through the expansion of regulatory T cells and suppression of Th17 cells. Eur J Immunol 37: 3021-3029, 2007.

16. Hu Y, Dong C, Yue Y and Xiong S: In vivo delivery of interleukin-35 relieves coxsackievirus-B3-induced viral myocarditis by inhibiting Th17 cells. Arch Virol 159: 2411-2419, 2014.

17. Terayama H, Yoshimoto T, Hirai S, Naito M, Qu N, Hatayama N, Hayashi S, Mitobe K, Furusawa J, Mizoguchi I, et al: Contribution of IL-12/IL-35 common subunit p35 to maintaining the testicular immune privilege. PLoS One 9: e96120, 2014.

18. Guan SY, Leng RX, Khan MI, Qureshi H, Li XP, Ye DQ and Pan HF: Interleukin-35: A potential therapeutic agent for autoimmune diseases. Inflammation 40: 303-310, 2017.

19. Wu X, Offenbacher S, López NJ, Chen D, Wang HY, Rogus J, Zhou J, Beck J, Jiang S, Bao X, et al: Association of interleukin-1 gene variations with moderate to severe chronic periodontitis in multiple ethnicities. J Periodontal Res 50: 52-61, 2015. 
20. Dutzan N, Gamonal J, Silva A, Sanz M and Vernal R: Over-expression of forkhead box P3 and its association with receptor activator of nuclear factor-kappa $\mathrm{B}$ ligand, interleukin (IL)-17, IL-10 and transforming growth factor-beta during the progression of chronic periodontitis. J Clin Periodontol 36: 396-403, 2009.

21. Joosten SA and Ottenhoff TH: Human CD4 and CD8 regulatory $\mathrm{T}$ cells in infectious diseases and vaccination. Hum Immunol 69: 760-770, 2008.

22. Ohlrich EJ, Cullinan MP and Seymour GJ: The immunopathogenesis of periodontal disease. Aust Dent J 54 (Suppl 1): S2-S10, 2009.

23. Alroqi FJ and Chatila TA: T regulatory cell biology in health and disease. Curr Allergy Asthma Rep 16: 27, 2016.

24. Collison LW, Chaturvedi V, Henderson AL, Giacomin PR, Guy C, Bankoti J, Finkelstein D, Forbes K, Workman CJ, Brown SA, et al: IL-35-mediated induction of a potent regulatory T cell population. Nat Immunol 11: 1093-1101, 2010.

25. Collison LW, Pillai MR, Chaturvedi V and Vignali DA: Regulatory $\mathrm{T}$ cell suppression is potentiated by target $\mathrm{T}$ cells in a cell contact, IL-35- and IL-10-dependent manner. J Immunol 182: 6121-6128, 2009.

26. Clavel G, Thiolat A and Boissier MC: Interleukin newcomers creating new numbers in rheumatology: IL-34 to IL-38. Joint Bone Spine 80: 449-453, 2013.

27. Ma J and Xie LZ: Eukaryotic expression and biological activity of human interleukin-35. Zhongguo Yi Xue Ke Xue Yuan Xue Bao 35: 618-622, 2013 (In Chinese).

28. Zhang YL, Zhou XY, Guo XY and Tu JW: Association between serum interleukin-35 levels and severity of acute pancreatitis. Int J Clin Exp Med 8: 7430-7434, 2015.
29. Egwuagu CE, Yu CR, Sun L and Wang R: Interleukin 35: Critical regulator of immunity and lymphocyte-mediated diseases. Cytokine Growth Factor Rev 26: 587-593, 2015.

30. Liu JQ, Liu Z, Zhang X, Shi Y, Talebian F, Carl JW Jr, Yu C, Shi FD, Whitacre CC, Trgovcich J and Bai XF: Increased Th17 and regulatory $\mathrm{T}$ cell responses in EBV-induced gene 3-deficient mice lead to marginally enhanced development of autoimmune encephalomyelitis. J Immunol 188: 3099-3106, 2012.

31. Tirotta E, Duncker P, Oak J, Klaus S, Tsukamoto MR, Gov L and Lane TE: Epstein-Barr virus-induced gene 3 negatively regulates neuroinflammation and $\mathrm{T}$ cell activation following coronavirus-induced encephalomyelitis. J Neuroimmunol 254: 110-116, 2013.

32. Kalburgi NB, Muley A, Shivaprasad BM and Koregol AC: Expression profile of IL-35 mRNA in gingiva of chronic periodontitis and aggressive periodontitis patients: A semiquantitative RT-PCR study. Dis Markers 35: 819-823, 2013.

33. Nakajima T, Ueki-Maruyama K, Oda T, Ohsawa Y, Ito $H$, Seymour GJ and Yamazaki K: Regulatory T-cells infiltrate periodontal disease tissues. J Dent Res 84: 639-643, 2005.

34. Olsen I: From the Acta Prize Lecture 2014: The periodontal-systemic connection seen from a microbiological standpoint. Acta Odontol Scand 73: 563-568, 2015.

35. Linden GJ and Herzberg MC; Working group 4 of the joint EFP/AAP workshop: Periodontitis and systemic diseases: A record of discussions of working group 4 of the joint EFP/AAP workshop on periodontitis and systemic diseases. J Periodontol 84 (4 Suppl): S20-S23, 2013.

36. Paquette DW: The periodontal infection-systemic disease link: A review of the truth or myth. J Int Acad Periodontol 4: 101-109, 2002. 